\title{
Distribution and health risk assessment of organochlorine pesticides (OCPs) in industrial site soils: A case study of urban renewal in Beijing, China
}

\author{
YANG Wenrui, WANG Rusong*, ZHOU Chuanbin, LI Feng \\ State key laboratory of Urban and Regional Ecology, Research Center for Eco-Environmental Sciences, Chinese Academy of Sciences, \\ Beijing 100085, China. E-mail: oydragon@126.com
}

Received 25 March 2008; revised 23 April 2008; accepted 10 June 2008

\begin{abstract}
A field survey was conducted in a contaminated industrial site of southern Beijing, China to investigate the contents and distribution of the organochlorine pesticides $\left(\alpha-, \beta-, \gamma-, \delta\right.$-HCH, $p, p^{\prime}$-DDT, $p, p^{\prime}$-DDE, $p, p^{\prime}$-DDD and $o, p^{\prime}$-DDT) in the profiles of soil, and a health risk assessment was carried out with CalTOX multimedia exposure model. Results showed that mean concentrations of total hexachlorocyclohexane isomers (HCHs) and total dichlorodiphenyltrichloroethane isomers (DDXs) in soils were in the range of 13.20$148.71 \mathrm{mg} / \mathrm{kg}$, and 3.02-67.43 mg/kg, respectively. Organochlorine pesticides (OCPs) content peaked in the surface and declined in soil profile with depth. The amounts of HCHs in three profiles of soil were larger than DDXs. Composition analysis indicated that there was a trend of degradation of OCPs in the site, but the mean of HCHs and DDXs concentration were over the state warning standard limit (HCHs, $0.50 \mathrm{mg} / \mathrm{kg}$; DDXs, $0.50 \mathrm{mg} / \mathrm{kg}$ ). According to current land use development, health risk assessment with CalTOX and Monte Carlo analysis showed that health risks mainly came from two exposure pathways: dermal uptake and inhalation, and the total risk values all exceeded the general acceptable health risk value $\left(10^{-6}\right)$. The sensitivity analysis indicated that five parameters significantly contributed to total risk.
\end{abstract}

Key words: pollution; hexachlorocyclohexane isomers (HCHs); dichlorodiphenyltrichloroethane isomers (DDXs); soil profiles; Monte Carlo; sensitivity

DOI: $10.1016 / \mathrm{S} 1001-0742(08) 62278-0$

\section{Introduction}

The usage of organochlorine pesticides (OCPs) has been banned in China more than 20 years because of their persistence (Dimond and Owen, 1996), bioaccumulation (Nakata et al., 2002) and toxicity to human and other animals and plants (Jones and de Voogt, 1999). In May 2001, dichlorodiphenyltrichloroethane was listed out by the Stockholm Convention as one of 12 persistent organic pollutants. China historically produced large amounts of hexachlorocyclohexane $(\mathrm{HCH})$ and dichlorodiphenyltrichloroethane (DDT) for agriculture. A total of 4.9 million tons of $\mathrm{HCH}$ and 0.4 million tons of DDT was produced from the 1950's through 1983 (Li et al., 2006), and occupied $33 \%$ and $20 \%$ of the global production for $\mathrm{HCH}$ and DDT, respectively (Hua and Shan, 1996; $\mathrm{Fu}$ et al., 2003). It was reported that about 14 million $\mathrm{hm}^{2}$ of farmland in China were considered polluted by organochlorine pesticides in 1983 (Feng et al., 2003). In last century, about 8000 tons of OCPs were used in agriculture in Beijing (Zhao and Ma, 2001), and from 1972 to 1974,610 tons of $\mathrm{HCH}$ and 190 tons of DDT were sold in suburbs of Beijing (Zhu et al., 2005).

\footnotetext{
* Corresponding author. E-mail: wangrs@ rcees.ac.cn
}

China is experiencing rapid urbanization and industrialization as cities are undergoing urban renewal, restoration and development, especially in capital city, Beijing. However, industrial development has contributed significant stress to both urban and natural environments during the last two decades (Zeng et al., 2001). A dozens of chemical plants located in southern Beijing until the end of last century, which caused serious air, water, and soil pollution. For the Beijing 2008 Olympic games, government commanded all chemical plants moved out of the city to improve environmental quality, but the residues left from the application of OCPs may still be harmful to the health of local residents. It is absolutely necessary to define the health risks of OCP's and quantify their distribution in the soils to help us prevent future impacts to human health.

Health risk assessment has been utilized for more than 30 years. In previous studies, most research has focused on the distribution of OCPs at regional scale. However, little research has exists to predict the risk to the residents' health based on OCPs residue distribution in contaminated industrial sites, particularly for the purpose of real estate development. This project aims to investigate the levels of OCPs in a typical contaminated industrial site soil and adopt the CalTOX multimedia exposure model to assess the human health risk. This research seeks to determine the 
OCPs residue distribution at the site and calculate the level of risk caused by OCPs contamination to human health. Assessing and modeling OCPs distribution may identify sensitive parameters by sensitivity analysis, which can provide the foundation for better environmental management and site exploitation to minimize health risks related to OCPs contaminated soil.

\section{Materials and methods}

\subsection{Site description}

The contaminated study site is located between the third and the forth ring road in southern Beijing and is surrounded by a residential area. The site measured roughly $40000 \mathrm{~m}^{2}$ and was occupied by a OCPs $(\mathrm{HCH}$ and DDT) pesticides plant until 1983. Now, this area is replaced by a paint factory. Future restoration and residential development are currently planned for the site.

\subsection{Sample collection}

Soil samples (118) was collected randomly from three soil layers: the surface $(0-20 \mathrm{~cm})$, the root zone $(20-200$ $\mathrm{cm})$ and the vadose zone $(200-400 \mathrm{~cm})$. Soils consisted of brown and sandy loam and silt loam. Soil samples were air-dried at room temperature and ground to pass through a 60 -mesh sieve. All samples were kept frozen at $-4^{\circ} \mathrm{C}$ until analysis and were subject for measurement of $\mathrm{HCHs}(\alpha-$ $\mathrm{HCH}, \beta-\mathrm{HCH}, \gamma-\mathrm{HCH}$, and $\delta-\mathrm{HCH})$ and DDXs $\left(p, p^{\prime}\right.$-DDT, $p, p^{\prime}$-DDE, $p, p^{\prime}$-DDD, and $\left.o, p^{\prime}-\mathrm{DDT}\right)$.

\subsection{Extraction and cleanup}

Soil sample (10 g) was weighed, put into centrifuge tubes and mixed with $30 \mathrm{~mL}$ acetone/petroleum ether solvent $(1: 1, V / V)$ before the mixture was extracted for 20 min with ultrasonic shaking apparatus (HH-500DB, Kunshan Hechuang ultrasonic instruments Corp., China). The mixture was centrifuged and the extracts were collected. The same extraction was repeated twice to the filter residue. All extracted solutions were concentrated to $1 \mathrm{~mL}$ by a rotary evaporator (R201, BUCHI Laboratory Equipment, Switzerland), and further purified with a glass column (12 mm i.d.) loaded with $5 \mathrm{~g}$ of activated florisil. The elution was subsequently carried out using $20 \mathrm{~mL}$ of hexane, followed by $100 \mathrm{~mL}$ of hexane containing $5 \%$ ethyl acetate $(V / V)$. The eluent was filtrated with anhydrous sodium sulfate. Finally, the solution was concentrated to 50 $\mathrm{mL}$ under a gentle steam of pure nitrogen.

\subsection{Analysis procedure and quality assurance}

The extracted samples were analyzed for OCPs using a PE Autosystem XL gas chromatograph (GC) (Perkin Elmer Auto System XL, USA) equipped with a HP-5 silica capillary column $(25 \mathrm{~m} \times 0.32 \mathrm{~mm}$ i.d. $\times 0.25 \mu \mathrm{m}$ film thickness) and a ${ }^{63} \mathrm{Ni}$ electron capture detector ( $\mu$-ECD). The oven temperature was maintained at $150^{\circ} \mathrm{C}$, raised to $180^{\circ} \mathrm{C}$ at a rate of $8^{\circ} \mathrm{C} / \mathrm{min}$, then programmed to $250^{\circ} \mathrm{C}$ at $20^{\circ} \mathrm{C} / \mathrm{min}$ and held for $5 \mathrm{~min}$. The injector and the detector were maintained at 250 and $300^{\circ} \mathrm{C}$, respectively. Nitrogen (purity $>99.999 \%$ ) was employed as the carrier gas at flow rate of $2.8 \mathrm{~mL} / \mathrm{min}$. GC peaks were identified based on the retention time of individual authentic standards. Quantification of OCPs was carried out by peak area measurements based on the external standards calibration curves.

The detection limits for soil samples are $0.0001 \mathrm{mg} / \mathrm{kg}$ for $\alpha-\mathrm{HCH}, 0.0002 \mathrm{mg} / \mathrm{kg}$ for $\beta-\mathrm{HCH}, 0.0001 \mathrm{mg} / \mathrm{kg}$ for $\gamma-\mathrm{HCH}, 0.0005 \mathrm{mg} / \mathrm{kg}$ for $\delta-\mathrm{HCH}, 0.0005 \mathrm{mg} / \mathrm{kg}$ for $p, p^{\prime}$-DDE, $0.0003 \mathrm{mg} / \mathrm{kg}$ for $o, p^{\prime}$-DDT, $0.0002 \mathrm{mg} / \mathrm{kg}$ for $p, p^{\prime}$-DDD, and $0.0005 \mathrm{mg} / \mathrm{kg}$ for $p, p^{\prime}$-DDT, respectively. Recoveries $\alpha-\mathrm{HCH}, \beta-\mathrm{HCH}, \gamma-\mathrm{HCH}, \delta-\mathrm{HCH}, p, p^{\prime}$-DDE, $o, p^{\prime}$-DDT, $p, p^{\prime}$-DDD, and $p, p^{\prime}$-DDT are $83.5 \%, 85.0 \%$, $87.6 \%, 91.2 \%, 93.8 \%, 94.2 \%, 90.1 \%$, and $88.1 \%$, respectively. The analysis of three blanks covering the entire analytical procedure (from the extraction to the GC analysis) was subjected to assess the interference from the reagents and glassware. GC analysis was repeated twice for each replicate sample and the relative standard deviation (RSD) of replicate samples were less than $15 \%$.

\subsection{Multimedia risk assessment model}

CalTOX is a multimedia, multiple pathway risk assessment model constructed by Californian Environmental Protection Agency used extensively to estimate chemical fate and human exposure to contaminants from polluted soil, air, ground water, surface water and sediment in the vicinity of hazardous waste sites (McKone, 1993; Bonnard, 2006). The model consists with the multimedia environmental fate model and multiple pathway exposure models. Eight environmental compartments were considered in the model: ambient air, groundwater, plant leaves, plant leaf surfaces, root-zone soil, the vadose zone soil below the root zone, surface water and sediments. Twentythree exposure pathways were also included (Chang et al., 2004).

To calculate the exposure dose and human risk, the model can be described by Eq. (1) (USEPA, 1989):

$$
\begin{array}{r}
H=\sum_{k}\left(1-\exp \left(\mathrm{ADI}_{k} \times \mathrm{CSF}_{k}\right)\right) \approx \\
\sum_{k} \mathrm{ADI}_{k} \times \mathrm{CSF}_{k}
\end{array}
$$

where, $H$ is the human health risk, $\operatorname{ADI}_{k}(\mathrm{mg} /(\mathrm{kg} \cdot \mathrm{d}))$ is the average daily intake of the contaminants by receptors through exposure route $k$ (inhalation, ingestion, or dermal absorption), $\operatorname{CSF}_{k}((\mathrm{~kg} \cdot \mathrm{d}) / \mathrm{mg})$ is the cancer slope factor of exposure route $k$, which is derived from dose-response studies (McKone, 1993).

When an environmental concentration is assumed constant over the exposure duration (ED), the populationaveraged potential dose (for ingestion or inhalation routes) or absorbed dose (for dermal contact) is the average daily dose rate $\left(\mathrm{ADI}_{i j k}\right)$.

$\mathrm{ADI}_{i j k}=C_{i} \times \frac{C_{j}}{C_{i}} \times \frac{\mathrm{IU}_{j k}}{\mathrm{BW}} \times \frac{\mathrm{EF} \times \mathrm{ED}}{\mathrm{AT}}$

where, $\mathrm{ADI}_{i j k}(\mathrm{mg} /(\mathrm{kg} \cdot \mathrm{d}))$ is the average daily intake from environmental media $i$ (air, soil or groundwater), exposure media $j$ (drinking water, food, etc.) and exposure route $k$ (inhalation, ingestion, or dermal abosorption), $C_{i}(\mathrm{mg} / \mathrm{kg})$ 
is the contaminant concentration in environmental medium $i, C_{j}(\mathrm{mg} / \mathrm{kg})$ is the pollution concentration in exposure media $j$. In this expression $C_{j} / C_{i}$ is the intermedia-transfer ratio, which expresses the ratio of contaminant concentration in the exposure medium $j$ to the concentration in an environmental medium $i, \mathrm{IU}_{j k}$ is the contact rate of exposure media $j$ through exposure route $k$, and $\mathrm{IU}_{j k} / \mathrm{BW}$ $\left(\mathrm{kg}^{-1}\right)$ is the intake or uptake factor per unit body weight associated with the exposure medium $j$, and route $k$. $\mathrm{EF}$ (d/year) is the exposure frequency, ED (year) is the exposure duration, AT (d) is the averaging time, and BW $(\mathrm{kg})$ is the body weights of receptors.

Ideally, all types of exposure pathways should be considered, but time and cost constraints prevented the inclusion of all parameters in the model. Site conceptual modeling can then be conducted to determine the significant exposure pathways by considering the chemical and landscape properties, as well as the fate/transport of chemicals (American Society for Testing and Materials, 2000). In Beijing, residents do not drink or directly use the ground and surface water, and most of the food is imported from outside of the city. Furthermore, the study site has no plant cover. Considering these factors, likely exposure pathways included dermal uptake, inhalation and direct soil ingestion.

CalTOX input parameters are included in Table 1 , the HCHs $(\alpha-, \beta-, \gamma-\mathrm{HCH})$ and DDXs ( $p, p^{\prime}$-DDT, $p, p^{\prime}$-DDE, $p, p^{\prime}$-DDD) parameters are CalTOX default parameters. Parts of landscape parameters were collected from the contaminated site.

Table 1 Landscape properties and exposure factors used in CalTOX model

\begin{tabular}{llll}
\hline Landscape property & Value & Exposure factors & Value \\
\hline $\begin{array}{l}\text { Site area } \\
\left(\mathrm{m}^{2}\right)\end{array}$ & 40000 & $\begin{array}{c}\text { Body weight } \\
(\mathrm{kg})\end{array}$ & 65 \\
$\begin{array}{c}\text { Ambient } \\
\text { temperature }(K)\end{array}$ & 286 & $\begin{array}{c}\text { Inhalation } \\
\text { rate }\left(\mathrm{m}^{3} / \mathrm{d}\right)\end{array}$ & 20 \\
$\begin{array}{c}\text { Water content in } \\
\text { root zone }(\%)\end{array}$ & 15 & $\begin{array}{c}\text { Lifetime } \\
\text { (year) }\end{array}$ & 70 \\
$\begin{array}{l}\text { Wind velocity } \\
(\mathrm{cm} / \mathrm{s})\end{array}$ & 312.5 & $\begin{array}{c}\text { Exposure duration } \\
\text { (year) }\end{array}$ & 20 \\
$\begin{array}{c}\text { Soil organic carbon } \\
\text { content }(\mathrm{g} / \mathrm{g})\end{array}$ & 0.0155 & $\begin{array}{c}\text { Surface area } \\
\left(\mathrm{m}^{2} / \mathrm{kg}\right)\end{array}$ & 0.026 \\
& & $\begin{array}{c}\text { Soil ingestion } \\
(\mathrm{mg} / \mathrm{d})\end{array}$ & 0.35 \\
\hline
\end{tabular}

Landscape properties are collected from environmental monitoring data of the contaminated site; exposure factors are default values of the CalTOX model.
A Monte Carlo technique was used to calculate the uncertainty of estimated risk by repeating a random sample 5000 times, which has been examined sufficient to avoid unacceptable variance in different realizations. Sensitivity analysis method was used to rank the input parameters on the basis of their contribution to variance in the output because information is a driving factor in the overall uncertainty of risk estimates for populations (Chen and Ma, 2006).

\section{Results and discussion}

\subsection{Content of HCHs and DDXs in the site}

Table 2 shows the concentration, arithmetic means, standard error (SE), minimum and maximum of OCPs in the soil samples. Because the production plants were distributed irregularly in the site, the concentration of $\sum \mathrm{HCHs}$ and $\sum \mathrm{DDX}$ s was also unevenly distributed. The concentration mean of $\sum$ OCPs in the contaminated site soil in the range $16.22-216.14 \mathrm{mg} / \mathrm{kg}, 13.20-148.71 \mathrm{mg} / \mathrm{kg}$ for $\sum \mathrm{HCHs}$, and $3.02-67.43 \mathrm{mg} / \mathrm{kg}$ for $\sum \mathrm{DDXs}$ in different layers. There were significant differences among the soil layers in total OCPs, with the highest concentrations in surface soil layer, decreasing with depth.

Figure 1 presents the percentages of $\mathrm{HCHs}$ ( $\sum \mathrm{HCHs}$ $=\alpha-\mathrm{HCH}+\beta-\mathrm{HCH}+\gamma-\mathrm{HCH}+\delta-\mathrm{HCH})$ and DDXs $\left(\sum \mathrm{DDXs}=p, p^{\prime}-\mathrm{DDD}+p, p^{\prime}-\mathrm{DDE}+p, p^{\prime}-\mathrm{DDT}+o, p^{\prime}-\right.$ DDT) isomers in vertical soil layers and it clearly shows that the $\sum \mathrm{HCH}$ were higher than $\sum \mathrm{DDX}$. In different soil layers, the $\sum \mathrm{HCHs}$ ranged from $68.81 \%$ to $81.31 \%$ while the $\sum$ DDXs ranged from $18.69 \%$ to $31.19 \%$. $\sum \mathrm{HCHs}$ were increasingly prevalent with depth. HCHs and DDXs

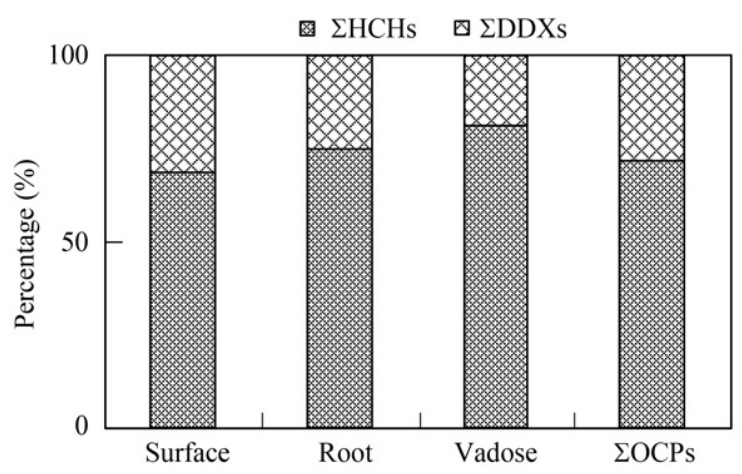

Fig. 1 Content of HCHs and DDXs in the industrial site.

Table 2 Concentration of organochlorine pesticides in soil profiles from contaminated site $(\mathrm{mg} / \mathrm{kg} \mathrm{dw})$

\begin{tabular}{|c|c|c|c|c|c|c|c|c|c|c|c|c|}
\hline & \multicolumn{4}{|c|}{ Surface } & \multicolumn{4}{|c|}{ Root zone } & \multicolumn{4}{|c|}{ Vadose zone } \\
\hline & Mean & SE & Max. & Min. & Mean & SE & Max. & Min. & Mean & SE & Max. & Min. \\
\hline$\alpha-\mathrm{HCH}$ & 43.97 & 19.07 & 957.31 & 0.02 & 42.29 & 22.69 & 880.98 & 0.01 & 5.41 & 4.49 & 161.67 & 0.01 \\
\hline$\beta-\mathrm{HCH}$ & 93.21 & 27.03 & 948.32 & 0.32 & 54.98 & 17.71 & 490.08 & 0.09 & 2.34 & 1.33 & 48.48 & 0.02 \\
\hline$\gamma-\mathrm{HCH}$ & 6.07 & 3.81 & 83.52 & 0.03 & 11.55 & 5.33 & 60.18 & 0.12 & 5.00 & 4.82 & 58.05 & 0.01 \\
\hline$\delta-\mathrm{HCH}$ & 5.46 & 2.15 & 61.03 & 0.02 & 3.04 & 1.04 & 15.68 & 0.06 & 0.45 & 0.19 & 2.04 & 0.04 \\
\hline$p, p^{\prime}-\mathrm{DDE}$ & 9.58 & 1.61 & 48.26 & 0.17 & 6.53 & 2.40 & 92.82 & 0.01 & 0.30 & 0.08 & 1.85 & 0.02 \\
\hline$p, p^{\prime}-\mathrm{DDD}$ & 23.84 & 11.14 & 446.08 & 0.08 & 12.89 & 7.81 & 235.01 & 0.02 & 1.31 & 0.83 & 15.24 & 0.02 \\
\hline$p, p^{\prime}$-DDT & 25.28 & 6.14 & 219.69 & 0.44 & 13.77 & 4.90 & 155.4 & 0.03 & 1.05 & 0.35 & 7.23 & 0.02 \\
\hline$o, p^{\prime}$-DDT & 8.73 & 2.31 & 83.43 & 0.13 & 4.11 & 1.48 & 48.57 & 0.02 & 0.36 & 0.09 & 0.95 & 0.05 \\
\hline$\sum \mathrm{OCPs}$ & 216.14 & & & & 149.16 & & & & 16.22 & & & \\
\hline
\end{tabular}


occupied $71.76 \%$ and $28.24 \%$ at the site, respectively. Differences between the incidence of these compounds can be explained by differences in their speed of metabolic degradation in the environment (Willett et al., 1998), and the production yield differences before the plant closed.

\subsection{Characteristics of OCPs in soil profiles and accu- mulation}

The concentration and distribution of OCPs at this site are subject to physical, chemical and biological processes such as biodegradation, chemical degradation, photolysis, leaching, adsorption, volatilization, etc. (Wang et al., 2006). HCHs and DDXs in soil may transfer to lower layers or stay in the surface soil, and both can cause long term negative effect on ecosystem and human health (Sun et al., 1997).

Figure 2a illustrates the vertical distribution of $\mathrm{HCH}$ isomers in three soil layers. The content of $\beta-\mathrm{HCH}$ in the upper two layers is higher than other isomers, and in the contaminated site, the total $\beta-\mathrm{HCH}$ is also higher than others. The content of different $\mathrm{HCH}$ isomers could be shown as $\beta-\mathrm{HCH}>\alpha-\mathrm{HCH}>\gamma-\mathrm{HCH}>\delta-\mathrm{HCH}$. But in the deep layer, there is little difference in $\mathrm{HCH}$ isomers distribution from the upper two layers, in that $\gamma$ $\mathrm{HCH}$ and $\alpha-\mathrm{HCH}$ have stronger penetration ability than $\beta-\mathrm{HCH}$ and $\delta-\mathrm{HCH}$ (Cooperation group, 1980), and they move downwards to more than $\beta-\mathrm{HCH}$ and $\delta-\mathrm{HCH}$. The typical $\mathrm{HCH}$ generally contains $60 \%-70 \%$ of $\alpha-\mathrm{HCH}$, $5 \%-12 \%$ of $\beta-\mathrm{HCH}, 10 \%-15 \%$ of $\gamma-\mathrm{HCH}$ and $6 \%-10 \%$ of $\delta$-HCH (Walker et al., 1999). The physicochemical properties of these $\mathrm{HCH}$ isomers are different, $\beta-\mathrm{HCH}$ has the lowest water solubility and vapor pressure, making it the most stable and relatively resistant to microbial degradation (Ramesh et al., 1991; Willett et al., 1998; Walker et al., 1999; Manz et al., 2001). However, it is the most persistent and least volatile isomer (Buser and Muller, 1995). The $\alpha-\mathrm{HCH}$ isomer can be converted to $\beta$ $\mathrm{HCH}$ in the environment (Wu et al., 1997; Walker et al., 1999) such that $\beta-\mathrm{HCH}$ tends to accumulate in the soil (Li, 1999). Figure 2b represents the content of different isomers of $\mathrm{HCH}$ at the contaminated site, it clearly shows that $\beta-\mathrm{HCH}$ was the dominant at the site, and $\alpha-\mathrm{HCH}, \beta-$ $\mathrm{HCH}, \gamma-\mathrm{HCH}$, and $\delta-\mathrm{HCH}$ occupied $34 \%, 55 \%, 8 \%$, and $3 \%$, respectively. Great changes occurred as compared to original components of $\mathrm{HCHs}$ because of its metabolic degradation, and the components of $\mathrm{HCH}$ isomers indicate that much $\alpha-\mathrm{HCH}$ is metabolized to the other isomers.

Figure 3a illustrates the DDXs' vertical distributions in the soil profiles. Similar to HCHs distribution patterns, the content of DDXs decreases with depth and in the order of $p, p^{\prime}$-DDT $>p, p^{\prime}$-DDD $>p, p^{\prime}$-DDE $>o, p^{\prime}$-DDT at the site. Technical DDT generally contains $75 \% p, p^{\prime}$-DDT, $15 \% o, p^{\prime}$-DDT, $5 \% p, p^{\prime}$-DDE, and $<5 \%$ others (Yang et al., 2005). Figure $3 \mathrm{~b}$ represents the content of different isomers of DDX at the site, which indicates that $p, p^{\prime}-$ DDT, $o, p^{\prime}$-DDT, $p, p^{\prime}$-DDE, and $p, p^{\prime}$-DDD occupied $37 \%$, $12 \%, 15 \%$, and $36 \%$ respectively. As contrast to DDXs technical components, there are great changes because of its metabolic transformation. In soil, DDT can be transformed to the stable and toxic metabolites DDD and DDE, while under anaerobic conditions, the DDT may transfer to DDD. Otherwise, DDT may transfer to DDE under aerobic conditions (Heberer and Dnnbier, 1999; Kalantzi et al., 2001). In our research the content of DDD was higher than DDE (Fig. 3b), indicating that the most probable degradation pathway transformed DDT to DDD.
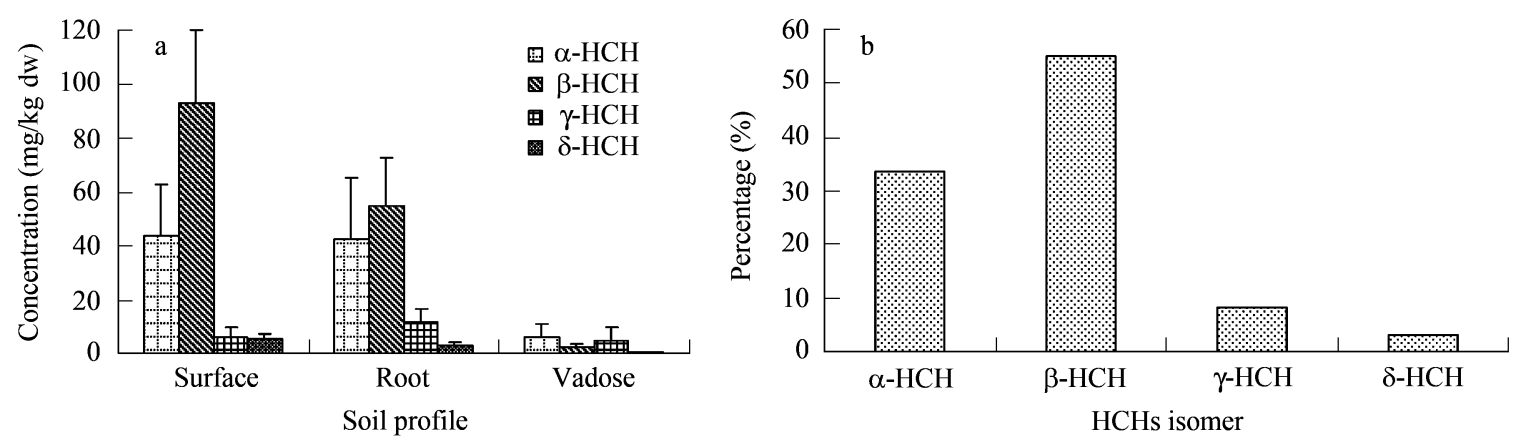

Fig. 2 Concentration of HCHs isomers in different soil profiles (a) and their percentage in the industrial site (b).
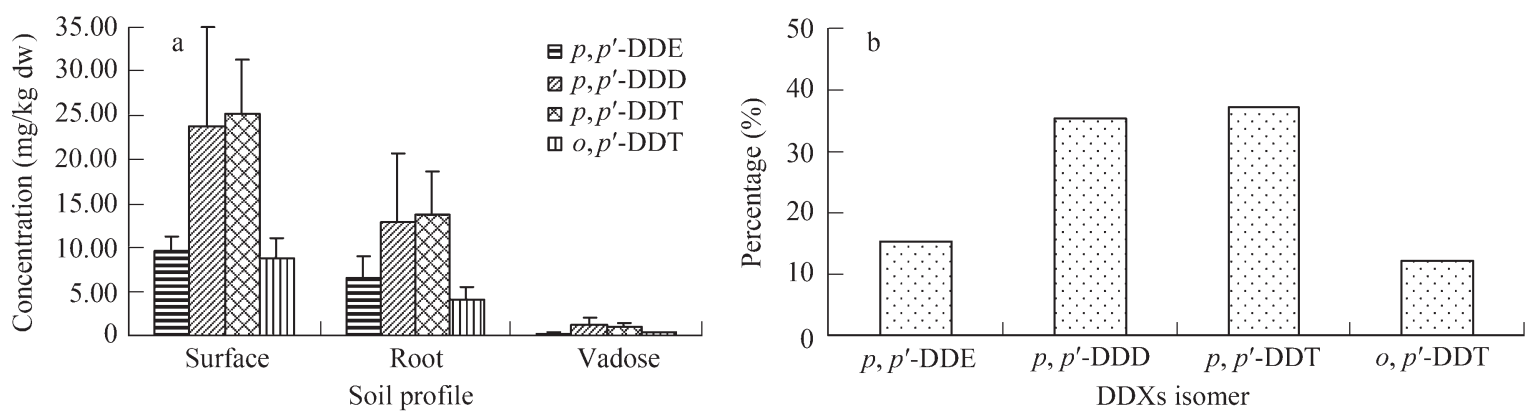

Fig. 3 Concentration of DDXs isomers in different soil profiles (a) and their percentage in the industrial site (b). 
Anaerobic metabolism probably dominated the DDT's transformation because the contaminated site is located in lowland that, in the past, was used as a rice paddy, having anaerobic soils. Studies have shown that DDXs have likely been subjected to a long-term weathering when the value of (DDE+DDD)/ $\sum \mathrm{DDX}$ s exceeds 0.5 (Hitch and Day, 1992; Hong et al., 1999). In the soil profiles at the contaminated site, the ratios of (DDE+DDD)/ $\sum D D X s$ were $0.50,0.52$, and 0.53 for three layers, respectively, from top to bottom, suggesting that the DDX's have degraded gradually. In an earlier study where the ratio reached to 0.76 (Yang et al., 2005). It was suggested that the ratio of (DDE+DDD)/ $\sum \mathrm{DDX}$ at the site would be greater as time goes by.

\subsection{Health risk assessment of OCPs in the site}

We calculated the health risk in different exposure pathways according to the predefined residential exposure scenarios. The 95th percentile risk distribution is often be considered to be the starting point for risk management (Presidential/Congressional Commission on Risk Assessment and Risk Management, 1997), and $10^{-6}$ is the generally acceptable lifetime health risk.

Table 3 shows the results of health risk assessment for the contaminated site studied. Although a great deal of effort has been made by CalTOX's developers to define default values or relationships to calculate default values for all the input parameters (Bonnard, 2006), and the values are necessary to calculate the health risk, it is not provides the parameters of $\gamma-\mathrm{HCH}$ and $o, p^{\prime}$-DDT. For this reason, we could not calculate the health risk from the two isomers. For different OCPs isomers, the human health risk values at 95 th percentile by three exposure pathways are different. As $\beta$-HCH, $p, p^{\prime}$-DDE, and $p, p^{\prime}$-DDT are concerned, except for direct ingestion, they contribute a great part of health risk by dermal contact and inhalation intake. For $\alpha-\mathrm{HCH}$ and $\gamma-\mathrm{HCH}$, both of them contribute health risk by inhalation pathway. Moreover, $p, p^{\prime}$-DDD contributes the health risk by dermal contact pathway. In all, the total risk from different pathway is ranked as: $p, p^{\prime}-\mathrm{DDT}>\beta-\mathrm{HCH}>p, p^{\prime}-\mathrm{DDE}>p, p^{\prime}-\mathrm{DDD}>\alpha-$ $\mathrm{HCH}>\gamma-\mathrm{HCH}$. Results indicate that health risk mainly occurs from dermal uptake and inhalation. Direct ingestion contributed least to the total risk, but is still a concern. This result contrasts with some previous studies that consider ingestion and inhalation as the predominant exposure pathways (Schuhmacher et al., 2001; Chang et al., 2004; Glorennec et al., 2005; Chen and Ma, 2006), likely because most of these assessments considered food chains as the exposure pathway. In this study, we did not prioritize food chains as an exposure pathway when predefining the exposure conditions; because the study area is in Beijing, where most of the residents' food are transported from outside the city, thus little health risk came from ingestion intake.

\subsection{Sensitivity analysis}

In order to rank the importance of influential factors in CalTOX model, we conducted sensitivity analysis using Crystal Ball 7.2 software (Decisioneering Inc., Denver, Colorado, USA).

Table 4 lists the significant ( $>1 \%$ ) variables. For $\mathrm{HCHs}$, the reaction half-life in root-zone soil (Thalf_s) was the most sensitive parameter, similar to results found for PAHs (Loranger and Courchesne, 1997). In CalTOX database (Mckone, 1993), the Thalf_s default values of $\alpha-\mathrm{HCH}, \beta$ $\mathrm{HCH}$, and $\gamma-\mathrm{HCH}$ are 46.9, 105, and $105 \mathrm{~d}$, respectively. In contrast, fraction dermal uptake from soil (dfct_sl) and exposure duration (ED) also played significant roles in health risk. For DDD and DDT, the soil adherence to skin (Slsk) and vapor pressure (VP) are also sensitive parameters. However, sensitivity analysis indicated that Thalf_s, dfct_sl, ED, EFsl, and Slsk are the most sensitive variables. Furthermore, the rank of these variables is different for different isomers due to the variability in soil characteristics and experimental conditions, under which Thalf_s were calculated (Jury et al., 1987).

Because of the persistence of OCPs in the soil and their transportation through environmental media, the implication of sensitivity in this study indicates that health risk would stem from the characters of OCP's themselves and human exposure parameters in the model; the environmental parameters are comparatively less sensitive. However, it must be emphasized that these values were drawn from the publications and other experiments.

Table 3 Risk values at 95th percentile for different exposure pathways in CalTOX model

\begin{tabular}{|c|c|c|c|c|c|}
\hline \multicolumn{2}{|c|}{ Exposure pathway } & \multirow{2}{*}{$\frac{\text { Dermal }}{8.72 \times 10^{-7}}$} & \multirow{2}{*}{$\frac{\text { Inhalation }}{2.58 \times 10^{-6}}$} & \multirow{2}{*}{$\frac{\text { Ingestion }}{1.13 \times 10^{-9}}$} & \multirow{2}{*}{$\frac{\text { Total risk }}{3.45 \times 10^{-6}}$} \\
\hline$\alpha-\mathrm{HCH}$ & Risk & & & & \\
\hline & Contribution & $25.27 \%$ & $74.70 \%$ & $0.03 \%$ & $100.00 \%$ \\
\hline \multirow[t]{2}{*}{$\beta-\mathrm{HCH}$} & Risk & $4.76 \times 10^{-6}$ & $1.21 \times 10^{-6}$ & $7.07 \times 10^{-9}$ & $5.98 \times 10^{-6}$ \\
\hline & Contribution & $79.59 \%$ & $20.29 \%$ & $0.12 \%$ & $100.00 \%$ \\
\hline \multirow[t]{2}{*}{$\gamma-\mathrm{HCH}$} & Risk & $8.71 \times 10^{-7}$ & $2.20 \times 10^{-6}$ & $1.32 \times 10^{-9}$ & $3.07 \times 10^{-6}$ \\
\hline & Contribution & $28.37 \%$ & $71.59 \%$ & $0.04 \%$ & $100.00 \%$ \\
\hline$\delta-\mathrm{HCH}, o, p^{\prime}-\mathrm{DDT}^{\mathrm{a}}$ & / & / & / & / & / \\
\hline \multirow[t]{2}{*}{$p, p^{\prime}-\mathrm{DDE}$} & Risk & $3.04 \times 10^{-6}$ & $2.59 \times 10^{-6}$ & $5.44 \times 10^{-9}$ & $5.64 \times 10^{-6}$ \\
\hline & Contribution & $53.91 \%$ & $45.99 \%$ & $0.10 \%$ & $100.00 \%$ \\
\hline \multirow[t]{2}{*}{$p, p^{\prime}-\mathrm{DDD}$} & Risk & $5.03 \times 10^{-6}$ & $1.81 \times 10^{-7}$ & $9.39 \times 10^{-9}$ & $5.22 \times 10^{-6}$ \\
\hline & Contribution & $96.35 \%$ & $3.47 \%$ & $0.18 \%$ & $100.00 \%$ \\
\hline \multirow[t]{2}{*}{$p, p^{\prime}-\mathrm{DDT}$} & Risk & $8.23 \times 10^{-6}$ & $3.18 \times 10^{-6}$ & $1.41 \times 10^{-8}$ & $1.14 \times 10^{-5}$ \\
\hline & Contribution & $72.06 \%$ & $27.82 \%$ & $0.12 \%$ & $100.00 \%$ \\
\hline
\end{tabular}

\footnotetext{
${ }^{a}$ No given parameter value in the CalTOX model.
} 
Table 4 Major parameters from the sensitivity analysis in the CalTOX model

\begin{tabular}{|c|c|c|c|c|c|c|}
\hline \multirow[t]{2}{*}{ Parameter } & \multicolumn{6}{|c|}{ Contribution to total risk $(\%)$} \\
\hline & $p, p^{\prime}-\mathrm{DDE}$ & $p, p^{\prime}-\mathrm{DDD}$ & $p, p^{\prime}$-DDT & $\alpha-\mathrm{HCH}$ & $\beta-\mathrm{HCH}$ & $\gamma$-HCH \\
\hline Thalf_s & 38.23 & 27.48 & 6.15 & 93.99 & 82.01 & 88.85 \\
\hline dfct_sl & 14.85 & 37.40 & 21.58 & - & 3.84 & 1.11 \\
\hline ED & 13.34 & 7.43 & 39.11 & - & 1.98 & 2.60 \\
\hline foc_s & 6.38 & - & 1.56 & 1.46 & 4.67 & 2.11 \\
\hline Efsl & 6.17 & 14.58 & 9.05 & - & 1.22 & - \\
\hline S & 3.76 & - & 2.05 & - & - & - \\
\hline Slsk & 3.02 & 8.27 & 4.91 & - & - & - \\
\hline$K_{\mathrm{oc}}$ & 2.91 & - & - & - & 1.46 & - \\
\hline $\mathrm{H}$ & 2.31 & - & 1.16 & - & - & - \\
\hline $\mathrm{BRa}$ & 2.09 & - & 1.24 & - & - & - \\
\hline VP & 1.39 & - & 6.84 & - & - & - \\
\hline
\end{tabular}

Thalf_s (d): reaction half-life in root-zone soil; dfct_sl: fraction dermal uptake from soil; ED (year): exposure duration; foc_s: organic carbon fraction in upper soil zone; EFsl (d/year): exposure frequency to soil on skin; $\mathrm{S}\left(\mathrm{mol} / \mathrm{m}^{3}\right)$ : solubility; Slsk $\left(\mathrm{mg} / \mathrm{cm}^{2}\right)$ : soil adherence to skin; $K_{\mathrm{oc}}$ : organic carbon partition coefficient $K_{\mathrm{oc}} ; \mathrm{H}\left(\left(\mathrm{Pa} \cdot \mathrm{m}^{3}\right) / \mathrm{mol}\right)$ : Henry's law constant; BRa $\left(\mathrm{m}^{3} /(\mathrm{kg} \cdot \mathrm{h})\right)$ : active breathing rate; VP $(\mathrm{Pa})$ : vapor pressure. $-:<1 \%$ variable.

\section{Conclusions}

In the last fifty years, organochlorine pesticides were extensively produced and used in China. This project focused on the OCPs plant site in Beijing, analyzed the OCPs distributions in the contaminated soil and estimated their risk to human health from different exposure pathways. The results showed that after the government prohibited the OCPs' production and usage, the content of OCPs in an industrial site decreased with depth of soil layers and most of them degraded to more stable and toxic isomers. The trend will be increased with the passage of time.

Our CalTOX evaluation, combined with Monte Carlo and sensitivity analysis, shows that there is unacceptable health risk at the site if the site is used for real estate development. Under a realistic, predefined exposure scenario corresponding to the conditions and customs of Beijing's urban residents, we found that health risks can be attributed to dermal uptake and inhalation. Sensitivity analysis shows that the reaction half-life in root-zone soil, fraction dermal uptake from soil, exposure duration, exposure frequency to soil on skin and soil adherence to skin are the most sensitive variables to total health risk because the most sensitive factors result from the chemical nature of different pollutants and from human exposure parameters. These results will enable environmental managers to reduce health risks to local residents. Our results suggest that risk management should be introduced to the contaminated site, and that pollutants should be removed from soils at the site to achieve an acceptable level for future development. In the meantime, our research shows that environmental managers should protect residents from direct dermal exposure to the soil pollutants.

\section{Acknowledgments}

This work was supported by the National Natural Science Foundation of China (No. 70433001); the Knowledge Innovation Project of the Chinese Academy of Sciences (No. KZCX2-YW-422, 324). The authors are grateful to Dr. Robin Marushia and Prof. Larry Li for reviewing the manuscript, and thank Prof. Jizheng He for his suggestions.

\section{References}

American Society for Testing and Materials, 2000. Standard guide for risk-based corrective action. E2081-00. West Conshohocken, PA.

Bonnard R, 2006. Risk communications: around the world common errors in the use of the CalTOX model to assess the human health risks linked to industrial emissions of pollutants. Human and Ecological Risk Assessment, 12(5): 1000-1010.

Buser H R, Muller M D, 1995. Isomer and enantioselective degradation of hexachlorocyclohexane isomers in sewagesludge under anaerobic conditions. Environmental Science and Technology, 29(3): 664-672.

Chang S H, Kuo C Y, Wang J W, Wang K S, 2004. Comparison of RBCA and CalTOX for setting risk-based cleanup levels based on inhalation exposure. Chemosphere, 56(4): 359367.

Chen Y C, Ma H W, 2006. Model comparison for risk assessment: A case study of contaminated groundwater. Chemosphere, 63(5): 751-761.

Cooperation group, 1980. Studies on pollution investigation and prevention measures in Beijing southeast suburbs [Collection] (1976-1979).

Dimond J B, Owen R B, 1996. Long-term residue of DDT compounds in forest soils in Maine. Environmental Pollution, 92(2): 227-230.

Feng K, Yu B Y, Ge D M, Wong M H, Wang X C, Cao Z H, 2003. Organo-chlorine pesticide (DDT and $\mathrm{HCH}$ ) residues in the Taihu Lake Region and its movement in soil-water system: I. Field survey of DDT and HCH residues in ecosystem of the region. Chemosphere, 50(6): 683-687.

Fu J M, Mai B X, Sheng G Y, Zhang G, Wang X M, Peng P A et al., 2003. Persistent organic pollutants in environment of the Pearl River Delta, China: An overview. Chemosphere, 52(9): 1411-1422.

Glorennec P, Zmirou D, Bard D, 2005. Public health benefits of compliance with current E.U. emissions standards for municipal waste incinerators: A health risk assessment with the CalTox multimedia exposure model. Environment International, 31(5): 693-701.

Heberer T, Dünnbier U, 1999. DDT metabolite bis(chlorophenyl) acetic acid: the neglected environmental contaminant. Environmental Science and Technology, 33(14): 2346-2351.

Hitch R K, Day H R, 1992. Unusual persistence of DDT in some 
western USA soils. Bulletin of Environmental Contamination Toxicology, 48(2): 259-264.

Hong H S, Chen W Q, Xu L, Wang X H, Zhang L P, 1999. Distribution and fate of organochlorine pollutants in the Pearl River Estuary. Marine Pollution Bulletin, 39(1-12): 376-382.

Hua X, Shan Z, 1996. Production and application of pesticides and factor analysis for their pollution in environment in China. Advance in Environmental Sciences, 4: 33-45.

Jones K C, de Voogt P, 1999. Persistent organic pollutants (POPs): state of the science. Environmental Pollution, 100(1-3): 209-221.

Jury W A, Winer A M, Spencer W F, Focht D D, 1987. Transport and transformations of organic chemicals in the soil-airwater ecosystem. Reviews of Environmental Contamination and Toxicology, 99: 119-164.

Kalantzi O I, Johnson P A, Santillo D, Stringer R L, Thomas G O, Jones K C, 2001. The global distribution of PCBs and organochlorine pesticides in butter. Environmental Science and Technology, 35(6): 1013-1018.

Li J, Zhang G, Qi S H, Li X D, Peng X Z, 2006. Concentrations, enantiomeric compositions, and sources of $\mathrm{HCH}$, DDT and chlordane in soils from the Pearl River Delta, South China. Science of the Total Environment, 372(1): 215-224.

Li Y F, 1999. Global technical hexachlorocyclohexane usage and its contamination consequences in the environment: from 1948 to 1997. Science of the Total Environment, 232(3): 121-158.

Loranger S, Courchesne Y, 1997. Health risk assessment of an industrial site contaminated with polycyclic aromatic hydrocarbons using CalTOX, an environmental fate/exposure model. SAR and QSAR in Environmental Research, 6(1): 81-104.

Manz M, Wenzel K D, Dietze U, Schuurmann G, 2001. Persistent organic pollutants in agricultural soils of central Germany. Science of the Total Environment, 277(1-3): 187-198.

McKone T E, 1993. CalTOX, a multimedia total exposure model for hazardous-waste sites; Part 1, Executive summary. Department of Toxic Substances Control, Lawrence Livermore National Laboratory, Livemore, CA, UCRL-CR-111456: 31.

Nakata H, Kawazoe M, Arizono K, Abe S, Kitano T, Shimada H, Li W, Ding X, 2002. Organochlorine pesticides and polychlorinated biphenyl residues in foodstuffs and human tissues from China: status of contamination, historical trend, and human dietary exposure. Archives of Environmental Contamination and Toxicology, 43(4): 473-480.
Presidential/Congressional Commission on Risk Assessment and Risk Management, 1997. Risk assessment and risk management in regulatory decision making. Final report. 2.

Ramesh A, Tanabe S, Murase H, Subramanian A N, Tatsukawa R, 1991. Distribution and behaviour of persistent organochlorine insecticides in paddy soil and sediments in the tropical environment: A case study in South India. Environmental Pollution, 74(4): 293-307.

Schuhmacher M, Meneses M, Xifro A, Domingo J L, 2001. The use of Monte-Carlo simulation techniques for risk assessment: study of a municipal waste incinerator. Chemosphere, 43(4-7): 787-799.

Sun W J, Cai J M, Huang B, 1997. The analysis of the pesticide residue in tea garden soil and tea leaves. Journal of Fujian Agricultural University, 26(1): 39-43.

USEPA, 1989. Risk Assessment Guidance for Superfund: Human Health Evaluation Manual, vol. 1 (Part A). Washington DC: Office of Emergency and Remedial Response.

Walker K, Vallero D A, Lewis R G, 1999. Factors influencing the distribution of lindan and other hexachlorocyclohexanes in the environment. Environmental Science and Technology, 33(24): 4373-4378.

Wang X J, Piao X Y, Chen J, Hu J D, Xu F L, Tao S, 2006. Organochlorine pesticides in soil profiles from Tianjin, China. Chemosphere, 64(9): 1514-1520.

Willett K L, Ulrich E M, Hites R A, 1998. Differential toxicity and environmental fates of hexachlorocyclohexane isomers. Environmental Science and Technology, 32(15): 21972207.

Wu W Z, Xu Y, Schramm K W, Kettrup A, 1997. Study of sorption, biodegradation and isomerization of $\mathrm{HCH}$ in stimulated sediment/water system. Chemosphere, 35(9): 1887-1894.

Yang R Q, Lv A H, Shi J B, Jiang G B, 2005. The levels and distribution of organochlorine pesticides (OCPs) in sediments from the Haihe River, China. Chemosphere, 61(3): 347-354.

Zeng F G, Wang W, Wu Y H, Li W, 2001. The research on PAHs in the atmosphere in Beijing Qianmen, Tiantan, Dingling District. Journal of the National Center University (Natural sciences Edition), 10(2): 162-166.

Zhao L, Ma Y J, 2001. Analysis of organochlorine pesticides residues in agricultural environment. Agro-Environment and Development, 18(1): 37-39.

Zhu Y F, Liu H, Xi Z Q, Cheng H X, Xu X B, 2005. Organochlorine pesticides (DDTs and $\mathrm{HCHs}$ ) in soils from the outskirts of Beijing, China. Chemosphere, 60(6): 770-778. 